\title{
Kütahya-Gediz Koşullarında Yetiştirilen Rezene (Foeniculum vulgare Mill.) Bitkisinin Uçucu Yağ Bileşenlerinin Belirlenmesi
}

\author{
Hasan Basri Karayel ${ }^{1 *}$ \\ ${ }^{1}$ Dumlupınar Üniversitesi Gediz Meslek Yüksekokulu. Tıbbi ve Aromatik Bitkiler, Kütahya, Türkiye (ORCID: 0000-0002-4271-0540) \\ (İlk Geliş Tarihi 7 Mart 2019 ve Kabul Tarihi 5 Mayıs 2019)
}

(DOI: 10.31590 /ejosat.)

ATIF/REFERENCE: Karayel, H. B. (2019). Kütahya-Gediz Koşullarında Yetiştirilen Rezene (Foeniculum vulgare Mill.) Bitkisinin Uçucu Yağ Bileşenlerinin Belirlenmesi. Avrupa Bilim ve Teknoloji Dergisi, (16), 131-135.

\section{Öz}

Bu araştırma, 2015 yılında Kütahya ili Gediz ilçesinde Rezene (Foeniculum vulgare Mill.) bitkisinin uçucu yağ bileşenlerini ve uçucu yağ oranını belirlemek amacıyla yürütülmüştür. Tarla denemeleri tesadüf blokları deneme desenine göre 3 tekerrürlü olarak kurulmuştur. Tohumlar $20 \mathrm{~cm}$ sıra arası ve $30 \mathrm{~cm}$ sıra üzeri mesafede dikilmiş yılda iki biçim yapılmıştır. Foeniculum vulgare Mill.'nin toprak üstü kısımlarının (Meyve) uçucu yağları analiz edilmiştir. Bu bitkilerin uçucu yağları hidrodestilasyon (GC_MS/FID) yoluyla elde edilmiştir. Lokasyondaki uçucu yağ oranı sırasıyla birinci ve ikinci biçim \%1,83 - \%1,51 olarak saptanmıştır. Uçucu yağda ana bileşen olarak birinci biçimde; trans-anethole \%85,82, limonene \%5,94, p-allylanisole \%4,26, fenchone \% 1,20, ikinci biçimde, trans-anethole $\% 91,08$, p-allylanisole \%4,18, limonene \%2,77 olarak tespit edilmiştir. Yapılan çalışma sonunda; uçucu yağ bileşenlerinin terbenler bakımından daha zengin olduğu saptanmıştır.

Anahtar Kelimeler: Foeniculum vulgare Mill., Uçucu yăg, Trans-anethole

\section{Determination of Essential Oil Components of Fennel (Foeniculum vulgare Mill.) Grown in Kütahya-Gediz Conditions}

\begin{abstract}
This research was carried out in 2015 in Kütahya-Gediz district in order to determine the volatile oil components ond volatile oil rates in the fennel plant (Foeniculum vulgare Mill.). Field experiments were repeated in 3 replicates according to randomized block design. The seedlings were planted by a horizontal distance of $30 \mathrm{~cm}$ and vertical distance of $20 \mathrm{~cm}$. The volatile oils of the above-ground parts of Foeniculum vulgare Mill. (fruit) were analyzed. This plant's volatile oil was obtained by hydrodistillation method (GC_MS/FID). The volatile oil rates for the first and second harvest were determined 1,83\% and 1,51\% respectively. The main components of the volatile oil were determined as follows for the first harvest; trans-anethole 85,82\%, Limonene 5,94\%, p-allylanisole 4,26\%, Fenchone $1,20 \%$ whereas these rates were as follows for the socond harvest; trans-anethole $91,08 \%$, p-allylanisole $4,18 \%$, Limonene $2,77 \%$. As a result of the study, the essential oil components were found to be richer in terpenes.
\end{abstract}

Keywords: Foeniculum vulgare Mill., Essential oil, Trans-anethole

\footnotetext{
${ }^{1}$ Sorumlu Yazar: Dumlupınar Üniversitesi Gediz Meslek Yüksekokulu. Tıbbi ve Aromatik Bitkiler, Kütahya kbasri23@hotmail.com, Türkiye, ORCID: 0000-0002-4271-0540, kbasri23@,hotmail.com
} 


\section{Giriş}

Tıbbi bitkiler son yıllarda hem ülkemizde hem de dünyada gıda, ilaç, parfüm ve kozmetik sektöründe çok amaçlı olarak kullanılmaktadır. Tıbbi bitkilerin kültürünün daha bilinçli yaygın şekilde yapılması gerekmektedir. Rezene tıbbi değeri olan önemli bir baharat bitkisidir. Rezenenin gıda ve baharat olarak kullanımının dışında, tedavi edici olduğundan dolayı ilaç olarak ta faydalanılmaktadır. Midevi, gaz söktürücü, süt çoğaltıcı ve yatıştırıcı özelliklere sahip olduğundan meyveleri infüzyon (\%1-2) veya toz halinde kullanılır (Baytop, 1984). Bir baharat ve ilaç bitkisi olan rezene; drog olarak bitkinin meyvelerine ilaveten yaprakları yara iyi edici, kökleri ise idrar artırıcı olarak kullanılır (Baytop,1999). Rezene üzerinde yapılan çalışmalar incelendiğinde meyvelerden elde edilen uçucu yağın antimikrobiyal, antioksidan, sekretolitik ve ekspektoran etkileri olduğu belirlenmiştir. Uçucu yağın ana bileşeni trans-anetol'ün östrojenik, lokal anestezik, anti-tümör ve anti-genotoksik etkilerinin bulunduğu görülmektedir (Escop, 2003). Ankara koşullarında tatlı rezene bitkisinde uçucu yağ oranı \%1,93-2,28 arasında değişim göstermiştir (Özkan, 1999). Bu çalışma 1998-2000 yıllarında taban ve kıraç alanlarda yetiştiriciliği yapılan rezene bitkisinin sonbahar ve ilkbaharda, tohum ekimleri ve pençe dikimleri yapılmıştır. En yüksek değerler; taban koşullarda, sonbaharda pençeyle çoğaltılan bitkilerden; kıraç koşullarda ise sonbaharda tohumla çoğaltılan bitkilerden elde edilmiştir. Denemenin ikinci yılında incelenen tüm özelliklerde değer artışı gözlenmiştir. Taban koşullarda pençeyle, kıraç koşullarda tohumla üretimin verim bakımından daha avantajlı olacağı belirlenmiştir (Oğuz, 2000). Karadağ'da yabani olarak yetişen rezene (Foeniculum vulgare Mill.)'de tohumların değişik ekstraksiyon şartlarında yapılan bir çalışmada elde edilen ekstreler su destilasyonu vasıtasıyla izole edilen rezene tohumu yağı ile karşılaştırılmıştır. SC-CO2'da, hidrodisitile yağdan, büyük bileşikler, sırasıyla trans-anetol $(\% 68,6-75,0)$ ve $(\% 62,0)$, metil kavikol $(\% 5,09-9,10)$ ve $(\% 4,90)$, ve fenchone $(\% 8,40-14,7)$ ve $(\%$ 20,3)'dür. Duyusal testler sudistilesi (hidrodistile yağların) yağların, SC-CO2 ile elde edilen ekstraktların, rezene tohumları aromasının daha az yoğun olduğunu doğrulamıştır (Damjanovic ve ark., 2005). Farklı koşullarda yetiştirilen rezene meyvelerinin uçucu yağ bileşenlerini inceledikleri bir çalışmada, meyvenin farklı kültür koşullarına bağlı olarak ana bileşenleri trans-anetol \%60,6-87,0, anisaldehit \%6,1-21,3, estragol \%3,2-11,7, $\alpha$-fenkon \%0,7-3,2, limonen \%0,3-2,5, karvon \%0,3-1,0 ve cis-anetol \%0,2-0,9 aralı̆gında bulunmuştur (Kan ve ark., 2006). Avrupa farmakopesinde hem tatlı hem de acı rezene meyvelerine ait monograf bulunmaktadır. F. vulgare var. vulgare'den en az $40 \mathrm{ml} / \mathrm{kg}$ uçucu yağ elde edilmelidir ve uçucu yağın bileşiminde en az \%60 anetol, en az \% 15 fenkon ve en fazla \%5 estragol içermelidir. F. vulgare var. dulce'den ise en az $20 \mathrm{ml} / \mathrm{kg}$ uçucu yağ elde edilmelidir ve uçucu yağın bileşiminde en az \%80 anetol, en fazla \%7,5 fenkon ve en fazla \%10 estragol içermesi gerektiği kayıtlıdır (European Pharmacopoeia, 2002).

$\mathrm{Bu}$ çalışmada Ülkemizde ekonomik olarak büyük bir öneme sahip olan rezene bitkisinin Kütahya-Gediz bölgesinin üretim deseninde yer almadığı, ancak yapılan bu çalışma ile bölgemizde rahatlıkla bir yılda iki biçim yapılabileceği, yapmış olduğumuz bu çalışmamızla belirlenmiştir. Yapılan bu çalışma sonucunda uçucu yağ miktarı ve uçucu yağ kompozisyonunun hangi biçim döneminde daha yüksek olduğu belirlenmeye çalışılmıştır.

\section{Materyal ve Metot}

\subsection{Deneme Yerinin İklim Ve Toprak Özelikleri}

Kütahya ili Gediz ilçesindeki lokasyonun toprak analizi Tablo 1'de verilmiştir. Lokasyonun Tablo 1're göre potasyum ve fosfor bakımında zengin olmadığı görülüyor. Kireç oranı yüksek bulunmuştur, organik madde bakımında fakir, toprak doygunluğu killi - tınlı olduğu analizler sonucunda belirlenmiştir (Anonim, 2015b).

Tablo 1. Deneme alanına ait toprak örneklerinde yapılan bazı kimyasal analiz sonuçları

\begin{tabular}{|l|l|l|}
\hline Analiz Tipi- kütahya & Sonuç & Durumu \\
\hline Potasyum (K2O) kg/da & 20,0123 & orta \\
\hline Fosfor (P2O5) Kg/da & 6,231 & orta \\
\hline Kireç(\%) & 4,0318 & Kireçli \\
\hline Organik Madde (\%) & 0,7862 & Çok az \\
\hline Toplam Tuz (\%) & 0,0035 & Tuzsuz \\
\hline PH & 7,14 & Nötr \\
\hline Saturasyon(\%) & 53,3 & Killi-Tınlı \\
\hline
\end{tabular}


Tablo 2. Deneme yerine ait 2015 yllina ilişkin Meteoroloji Rasat Cetveli

\begin{tabular}{|c|c|c|c|c|c|c|c|c|c|c|c|c|c|}
\hline & & \multicolumn{12}{|c|}{ Aylar } \\
\hline \multirow{2}{*}{$\begin{array}{l}\text { Aylık } \\
\text { ortalama } \\
\text { sicaklık }{ }^{\circ} \mathrm{C}\end{array}$} & Yil & 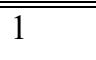 & 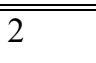 & 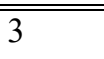 & 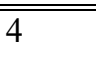 & $\bar{~} \overline{5}$ & 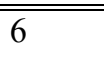 & $\overline{7 \overline{7}}$ & 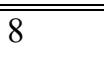 & $\overline{99}$ & 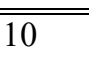 & $\overline{11}$ & $\overline{12}$ \\
\hline & $\begin{array}{l}201 \\
5\end{array}$ & 2,5 & 4,3 & 7,4 & 9,4 & 17,5 & 19,0 & 24,8 & 24,5 & 22,5 & 15,2 & 9,7 & 3,2 \\
\hline $\begin{array}{c}\text { Aylık } \\
\text { ortalama } \\
\text { nem }(\%)\end{array}$ & $\begin{array}{c}201 \\
5\end{array}$ & 82,1 & 77 & 77,2 & 63,4 & 60,6 & 71,9 & 50,8 & 57,7 & 56,9 & 68,7 & 66,9 & 69,5 \\
\hline $\begin{array}{c}\text { Aylık } \\
\text { ortalama } \\
\text { Yağış } \\
(\mathrm{mm})\end{array}$ & $\begin{array}{c}201 \\
5\end{array}$ & 0 & 29,6 & 76,8 & 31 & 72,8 & 90,7 & 7,8 & 51,1 & 10,2 & 25,8 & 60,8 & 0,4 \\
\hline
\end{tabular}

*Devlet Meteoroloji işleri Genel Müdürlüğü Aylık Klimatoloji Rasat Cetveli

Kütahya ili Gediz ilçesi yazları sıcak ve kurak, kışlar soğuk ve yağışlı bir iklime sahiptir. Gediz 'de Tablo 2'deki verilere göre en sıcak aylar, Temmuz ve Ağustos, en soğuk aylar Ocak ve Şubattır. En düşük ölçülen sıcaklık ise 2,5 0C dir. Yıllık yağış miktarı 457,08 mm'dir. En yağışlı ay Mayıs-Haziran, en kurak ay Eylül dür (Anonim., 2015a). İç Ege bölgesinde bulunan Kütahya'da karasal iklim hâkimdir ama Gediz ilçesinde ılıman bir iklim hakimdir bu neden dolayı uçucu yağ kompozisyonu iklim durumuna göre olumlu veya olumsuz olarak etkilenir.

\subsubsection{Bitki Materyali}

Bu çalışmada materyal olarak kullanılan tohumlar Tokat Gaziosmanpaşa Üniversitesi Ziraat Fakültesi Tarla Bitkileri Bölümünde temin edilmiştir. Deneme Kütahya Dumlupınar üniversitesi Gediz Meslek Yüksekokulu Uygulama alanında yürütülmüştür. Tohumlar 2015 yılı Mart ayının ilk haftasında deneme alanına direk ekilmiştir. Tohumların çimlenmesi 15-20 gün sürmüştür. Tarla denemeleri tesadüf blokları deneme desenine göre 3 tekerrürlü olarak yürütülmüştür. Bitki dikim sıklığ $20 \mathrm{~cm}$ sıra arası, $30 \mathrm{~cm}$ sıra üzeri mesafelerine göre düzenlenmiş, her parsel 3 sıradan oluşmuştur. Her sıraya 24 bitki olmak üzere, bir parsele $24 \times 3=72$ bitki ekilmiştir. Bitkiler çimlenene kadar hortumla sulanmış. Gözlemler ve ölçümler her parselde sağlıklı 60 bitki içerisinde etiketlenen 10 adet bitkiden elde edilen meyve örneklerinde yapılmıştır. Bir yılda iki biçim yapılmıştır. Birinci biçim 10.07. 2015 tarihinde rezene meyvelerinin olgunlaşmaya başlandığı zaman hasat edilmiştir. Uçucu yağ oranı hasat edilen rezene meyvelerinin tanelerinde elde edilmiştir. Hasat toprak üstüne paralel olacak şekilde $10 \mathrm{~cm}$ yükseklikte kesilerek hasat edildi. Kökler (pençeler) toprakta kaldı ve tekrar sulanmaya başlandı bir hafta sonra tekrar rezene bitkisi yavaş yavaş büyümeye başlamıştır. İkinci hasat 25.10.2015 tarihinde yapılmıştır. İkinci hasatta gün sayısının düşük olmasının nedeni birinci hasatta toprakta kalan kökler (pençeler) bitkinin büyüme hızını etkilemiş ikinci hasat tarihini azda olsa öne çekmiştir.

\subsubsection{Uçucu Yağ Elde Edilmesi}

Deneme uçucu yağ analizinin başlangıcında $20 \mathrm{~g}$ kuru materyal tartılarak $500 \mathrm{ml}$ 'lik balona alınmıştır. Üzerine $200 \mathrm{ml}$ (örnek miktarına göre değişebilir, yaklaşık 10 kat) saf su eklenip çalkalanmıştır. İki saat süreyle hidrodestilasyon işlemine tabi tutularak uçucu yağ elde edilmiştir. Sistem soğuduktan sonra ve dereceli kısma toplanan uçucu yağ sulu fazdan ayrıldıktan sonra miktarı (ml) tespit edilmiştir. Tartımı alınan örnek miktarına (g) göre $100 \mathrm{~g}$ örnekteki uçucu yağ miktarı uçucu yağ oranı (\%) olarak hesaplanmıştır (Skoula ve ark., 2000).

\subsubsection{Uçucu Yağ Kompozisyonunun GC-MS ile Belirlenmesi}

Örnekler 1:100 oranında hekzan ile seyreltilip Gaz kromatografisi (Agilent 7890A) cihazına $1 \mu$ lolarak 40:1 split oranı ile enjekte edilmiştir. Bileşenlerin ayrımı için kapiler kolon (HP InnowaxCapillary; $60.0 \mathrm{~m}$ x $0.25 \mathrm{~mm}$ x $0.25 \mu \mathrm{m}$ ) kullanılmıştır. Kolon, bitiminde bir ayraç (splitter) yardımıyla FID ve kütle spektrometresi dedektörüne (Agilent 5975C) akış 1:1 oranında olacak şekilde ikiye ayrılmıştır. Analizde taşıyıcı gaz olarak $0.8 \mathrm{ml} / \mathrm{dk}$ akış hızında helyum kullanılmıştır. Enjektör sıcaklığ $250^{\circ} \mathrm{C}$ 'de tutulmuş, kolon sicaklık program $-60^{\circ} \mathrm{C}^{\prime}$ de 10 dakika, $60^{\circ} \mathrm{C}^{\prime}$ den $220^{\circ} \mathrm{C}$ 'ye $4^{\circ} \mathrm{C} /$ dakika ( 40 dakika) ve $220^{\circ} \mathrm{C}$ 'de 10 dakika - toplamda 60 dakika olacak şekilde ayarlanmıştır. Kütle detektörü için tarama aralı̆̆ı $(\mathrm{m} / \mathrm{z}) 35-450$ atomik kütle ünitesi ve elektron bombardımanı iyonizasyon enerjisi 70 eV'dir. Uçucu yağın bileşenlerinin teşhisinde OIL ADAMS, WILEY ve NIST kütüphanelerinin verileri esas alınmıştır. Uçucu yağ bileşen oranlarında ise FID dedektörünün verileri kullanılmıştır (Özek ve ark., 2010). 


\section{Araştırma Sonuçları ve Tartışma}

Bu çalışmada, Rezene bitkisinin (Foeniculum vulgare Mill.) meyvelerindeki uçucu yağ oranı ve kompozisyonunun birinci ve ikinci biçimde elde edilen oranları sırasıyla \%1,83-1,51 olarak ölçülmüştür.

\subsection{Uçucu Yă̆ Oram (\%)}

Uçucu yă̆ oranı konusunda yapılan çalışmalarda; Ankara Üniversitesi Ziraat Fakültesi Tarla Bitkileri Bölümünde yapılan çalışmada uçucu yağ oranı \% 1,93-2,28 arasında değişim göstermiştir (Özkan, 1999). Samsun ekolojik şartlarında yapılan çalışmada ise \%2,43 olarak tespit edilmiştir (Karaca ve Kevseroğlu, 2001). Rezene bitkisinin (Foeniculum vulgare Mill.) önemli bazı özelliklerini belirlemek amacıyla yapılan bu çalışmada uçucu yağ oranı \%1,51-1,69 aralığında bulunmuştur (Arabacı ve Bayram, 2005). Farklı yetiştirme dönemlerinde rezene tohumlarının uçucu yağ oranı \%1,18-1,31 arasında değişiklik göstermiştir (Saharkhiz ve Tarakeme, 2011). Birinci ve ikinci biçimde elde edilen uçucu yağ oranı yapılan diğer çalışmalarla karşılaştırıldığında benzer bulunmuştur.

\subsection{Uçucu Yağın Bileşimi (\%)}

Rezene (Foeniculum vulgare Mill.) meyvelerinde elde edilen uçucu yağın analizinde birinci ve ikinci biçimde sırasıyla 7 ve 6 bileşen tanımlanmıştır. Bu bileşenler toplam yağın birinci biçimde \%98,94, ikinci biçimde \%99,99'luk kısmını oluşturmuştur. Rezene (Foeniculum vulgare Mill.) türüne ait meyvelerinde elde edilen uçucu yağ oranı ve uçucu yağ bileşenlerin değerleri birinci yıl iki biçimde elde edilen örneklerde belirlenmiştir. Rezene (Foeniculum vulgare Mill.) türünün uçucu yağ bileşenlerin değerleri ayrı ayrı olacak şekilde Çizelge 3.2.1'de gösterilmiştir. Rezene (Foeniculum vulgare Mill.) bitkisinin birinci biçim ortalamasında elde edilen uçucu yağ ana bileşenleri; trans-anethole \%85,82, limonene \%5,94, p-allylanisole \%4,26, ikinci biçim ortalamasında elde edilen uçucu yağ ana bileşenleri; trans-anethole $\% 91,08$, limonene $\% 2,77$, p-allylanisole $\% 4,18$, değişim göstermiştir. Biçim (Meyvede) sayısına göre uçucu yağın ana bileşenleri sırasıyla, trans-anethole, limonene, p-allylanisole, olarak bulunmuştur. Rezene bitkisinin biçim sayısına göre uçucu yağ bileşenleri belli oranda değişiklik göstermiştir. Foeniculum vulgare Mill. türünün ana bileşeni trans-anethole olarak gerçekleşmiştir. Foeniculum vulgare Mill. türünün ana bileşenleri Çizelge 3.2.1'de verilmiştir. Çalışmamız benzer şekilde; Damjanoviz ve ark. (2005)'nın Karadağ'da yabani olarak yetişen rezene tohumları üzerine yaptıkları araştırmada trans-anethole miktarını \%68,6 ile \%75,0 aralığında bulunmuştur. Kan ve ark. (2006), farklı kültür koşullarına bağlı olarak rezene bitkisinin uçucu yağındaki ana bileşenler sırasıyla, trans-anetol \%60,6-87,0, anisaldehit \%6,1-21,3, estragol \%3,2-11,7, $\alpha$-fenkon \%0,7-3,2, limonen $\% 0,3-2,5$, karvon \% 0,3-1,0 ve cis-anetol \%0,2-0,9 olduğunu tespit etmişlerdir.

Çizelge 3.2.1. Foeniculum vulgare Mill. türünün (2015 yılı) uçucu yağının biçim sayısına göre bileşen miktarının (\%)

değişimi

\begin{tabular}{|c|c|c|c|}
\hline \multirow[b]{2}{*}{ S.no } & \multirow[b]{2}{*}{ Bileşen adı } & \multicolumn{2}{|c|}{ Meyve } \\
\hline & & 1.Biçim & 2.Biçim \\
\hline & 1-Limonene & $5,94 \pm 0,14142$ & \\
\hline & 2-cis-ocimene & $0,25 \pm 0,14142$ & - \\
\hline & 3-Fenchone & $1,20 \pm 0,021213$ & $1,33 \pm 0,021213$ \\
\hline & 4-p-allylanisole & $4,26 \pm 0,014142$ & $4,18 \pm 0,028284$ \\
\hline & 5-Carvone & $0,56 \pm 0,035355$ & $0,28 \pm 0,021213$ \\
\hline & 6-trans-anethole & $85,82 \pm 0,141421$ & $91,08 \pm 0,311127$ \\
\hline & 7-p-anisaldehyde & $0.91 \pm 0,657609$ & $0,35 \pm 0,021213$ \\
\hline & Toplam (\%) & $\% 98,94$ & $\% 99,99$ \\
\hline
\end{tabular}

Farklı gelişme dönemlerinde rezene tohumlarının uçucu yağ içeriği ve bileşenleri üzerine yapılan bir çalışmada ana bileşen olarak, trans- anethole'nin farklı olgunlaşma dönemlerine göre \%84-\%86 aralığında değişim göstermiştir (Saharkhiz ve Tarakeme, 2011). Farklı (Norveç, Estonya, Avusturya, Moldovya, Türkiye ) ülkelerde temin edilen rezene örneklerinin uçucu yağ içeriği incelenmiş olup, transanethol oranı en yüksek (\%82) Estonya, en düşük Türkiye'de (\%34) toplanan örneklerde bulunmuştur. Bitkilerin yetiştirildiği ekolojik şartlara göre yağ bileşenlerinde önemli değişikliklerin olduğu sonucuna varılmıştır (Raal ve ark., 2012). Birinci ve ikinci biçimde elde edilen trans-anethole oranı yapılan diğer çalışmalarla karşılaştırıldığında benzer bulunmuştur. 


\section{Sonuç}

Araştırmanın sonuçuna göre, Kütahya-Gediz bölgesinde yapılan çalışmada Foeniculum vulgare Mill. türünün meyvelerinde elde edilen uçucu yağ oranları ve uçucu yağların bileşenleri belirlenmiştir. Uçucu yağ oranı en yüksek birinci biçimde \%1,83 olduğu tespit edilmiştir. Foeniculum vulgare Mill. türünün meyvelerinde birinci biçimde elde edilen ana bileşen trans-anethole \%85,82 (Temmuz ayında ortalama sıcaklık 24,5 oC), ikinci biçimde trans-anethole \%91,08 (Ekim ayında 15,2 oC) olarak değişim göstermiştir. İkinci biçimde trans-anethole yüksek çıkmasının sebebi iklim değişimi gösterilebilir. İkinci biçimde en yüksek olan trans-anethole en önemli ana bileşen olduğundan dolayı, bu bileşen için ikinci biçim önerilebilir. Kütahya ili Gediz ilçesinde tarımı yapılan Foeniculum vulgare Mill. türünün uçucu yağ oranı ve kalitesi bakımından oldukça verimli olduğu söylenebilir.

\section{Kaynakça}

Anonim, 2015a. İklim Verileri. Kütahya Meteoroloji İl Müdürlüğü, Kütahya.

Anonim 2015b. Toprak Analizi Sonuçları. Kütahya Ziraat Odası Başkanlığı, Kütahya.

Arabacı, O., Bayram, E. 2005. Farklı Sıra Arası ve Tohumluk Miktarlarında Kişniş (Coriandrum sativum L.)'in Bazı Morfolojik ve Teknolojik Özelliklerinin Belirlenmesi,Türkiye VI. Tarla Bitkileri Kongresi, Antalya, 535-540.

Baytop, T. 1984. Türkiye' de Bitkiler İle Tedavi. İstanbul Üniv. Yay. No: 3255, Ecz. Fak. Yay. No: 40,İstanbul.

Baytop, T. 1999. Türkiye'de Bitkilerle Tedavi. Nobel Tıp Kitabevleri, 2. bask1, s. 320.

Damjanovic, B., Lepojevic, Z., Zivkovic, V., Tolic, A. 2005. Extraction of fennel (Foeniculum vulgare Mill.) seeds with supercritical CO2: Comparison with hydrodistillation, Food Chemistry, 92, 143-149.

European Pharmacopoeia, 4th edition, Council of Europe, Strasbourg (2002).

Escop, Escop Monographs, 2nd edition, Thieme, New York, 162-168 (2003).

Kan, Y., Kartal, M., Aslan, S., Yıldırım, N. 2006. Farklı koşullarda Yetiştirilen Rezene Meyvelerinin Uçucu Yağ Bileşenleri, Ankara Üniversitesi Eczacılık Fakültesi Dergisi, 35 (2), 95-101.

Karaca,A., Kevseroğlu, K. 2001. Kişniş (Coriandrum sativum L.) ve Rezene (Foeniculum vulgare Mill.) Bitkilerinde Fenolojik, Morfolojik ve Bazı Teknik Özellikler Üzerinde Araştırmalar, Türkiye 4. Tarla Bitkileri Kongresi, Tekirdağ, $243-248$.

Oğuz, A. 2000. Rezene (Foeniculum vulgare var. dulce)'de Farklı Yetiştirme Yöntemlerinin Verim ve Uçucu Yağ Oranına Etkisi, Çukurova Üniversitesi Fen Bilimleri Enstitüsü, Adana, I.

Özkan, F. 1999.Tatlı Rezene (Foeniculum vulgare Mill. Var. Dulce)'de Bitki Sıklığının Verim ve Verim Öğeleri Üzerine Etkileri, Yüksek Lisans Tezi, Ankara Üniversitesi Fen Bilimleri Enstitüsü, Ankara, I.

Özek, T.,Tabanca,N., Demirci,F., David E. Wedgeand K. Hüsnü Can Başer. 2010. Enantiomeric Distribution of Some Linalool Containing Essential Oil sand Their Biological Activities. Rec. Nat. Prod. 4:4. 180-192.

Raal, A., Orav, A., Arak, E. 2012, Essential Oil Composition of Foeniculumvulgare Mill. Fruits From Pharmacies in Different Countries, Natural Product Research, 26 (13), 1173-1178.

Saharkhiz, M.J., Tarakeme, A. 2011, Essential Oil Content and Composition of Fennel (Foeniculum vulgare L.) Fruits at Different Stages of Development,Journal Of Essential Oil Bearıng Plants, 14 (5), 605-609.

Skoula, M., J. E. Abbes, C. B. Johnson. 2000. Genetic variation of volatile sandros marinicacidin populations of Salvia fruticosa Mill, growing in Crete.Journal of Biochemica 1Syste matics and Ecology, 28:551-561. 